\title{
RESEARCH
}

Open Access

\section{Influence of the mesenchymal stromal cell source on the hematopoietic supportive capacity of umbilical cord blood-derived CD34 ${ }^{+}$-enriched cells}

Sara Bucar ${ }^{1,2}$, André Dargen de Matos Branco ${ }^{1,2}$, Márcia F. Mata', João Coutinho Milhano ${ }^{3}$, Íris Caramalho ${ }^{4}$, Joaquim M. S. Cabral ${ }^{1,2}$, Ana Fernandes-Platzgummer ${ }^{1,2}$ and Cláudia L. da Silva ${ }^{1,2^{*}}$ (i)

\begin{abstract}
Background: Umbilical cord blood (UCB) is a clinically relevant alternative source of hematopoietic stem/ progenitor cells (HSPC). To overcome the low cell number per UCB unit, ex vivo expansion of UCB HSPC in coculture with mesenchymal stromal cells (MSC) has been established. Bone marrow (BM)-derived MSC have been the standard choice, but the use of MSC from alternative sources, less invasive and discardable, could ease clinical translation of an expanded $\mathrm{CD}_{4} 4^{+}$cell product. Here, we compare the capacity of BM-, umbilical cord matrix (UCM)-, and adipose tissue (AT)-derived MSC, expanded with/without xenogeneic components, to expand/maintain UCB CD34+-enriched cells ex vivo.

Methods: UCB CD34 ${ }^{+}$-enriched cells were isolated from cryopreserved mononuclear cells and cultured for 7 days over an established feeder layer (FL) of BM-, UCM-, or AT-derived MSC, previously expanded using fetal bovine serum (FBS) or fibrinogen-depleted human platelet lysate (HPL) supplemented medium. UCB cells were cultured in serum-free medium supplemented with SCF/TPO/FLT3-L/bFGF. Fold increase in total nucleated cells (TNC) as well as immunophenotype and clonogenic potential (cobblestone area-forming cells and colony-forming unit assays) of the expanded hematopoietic cells were assessed.

Results: MSC from all sources effectively supported UCB HSPC expansion/maintenance ex vivo, with expansion factors (in TNC) superior to 50x, 70x, and 80x in UCM-, BM-, and AT-derived MSC co-cultures, respectively. Specifically, AT-derived MSC co-culture resulted in expanded cells with similar phenotypic profile compared to BMderived MSC, but resulting in higher total cell numbers. Importantly, a subpopulation of more primitive cells $\left(\mathrm{CD}_{34}{ }^{+} \mathrm{CD} 90^{+}\right)$was maintained in all co-cultures. In addition, the presence of a MSC FL was essential to maintain and expand a subpopulation of progenitor T cells $\left(\mathrm{CD} 34^{+} \mathrm{CD} 7^{+}\right)$. The use of HPL to expand MSC prior to co-culture establishment did not influence the expansion potential of UCB cells.
\end{abstract}

\footnotetext{
* Correspondence: claudia_lobato@tecnico.ulisboa.pt

'Department of Bioengineering and iBB - Institute for Bioengineering and

Biosciences, Instituto Superior Técnico, Universidade de Lisboa, Lisboa,

Portugal

${ }^{2}$ Associate Laboratory i4HB - Institute for Health and Bioeconomy, Instituto

Superior Técnico, Universidade de Lisboa, Lisboa, Portugal

Full list of author information is available at the end of the article
}

\section{$\triangle B M C$}

(c) The Author(s). 2021 Open Access This article is licensed under a Creative Commons Attribution 4.0 International License, which permits use, sharing, adaptation, distribution and reproduction in any medium or format, as long as you give appropriate credit to the original author(s) and the source, provide a link to the Creative Commons licence, and indicate if changes were made. The images or other third party material in this article are included in the article's Creative Commons licence, unless indicated otherwise in a credit line to the material. If material is not included in the article's Creative Commons licence and your intended use is not permitted by statutory regulation or exceeds the permitted use, you will need to obtain permission directly from the copyright holder. To view a copy of this licence, visit http://creativecommons.org/licenses/by/4.0/ The Creative Commons Public Domain Dedication waiver (http://creativecommons.org/publicdomain/zero/1.0/) applies to the data made available in this article, unless otherwise stated in a credit line to the data. 
Conclusions: AT represents a promising alternative to BM as a source of MSC for co-culture protocols to expand/ maintain HSPC ex vivo. On the other hand, UCM-derived MSC demonstrated inferior hematopoietic supportive capacity compared to MSC from adult tissues. Despite HPL being considered an alternative to FBS for clinical-scale manufacturing of MSC, further studies are needed to determine its impact on the hematopoietic supportive capacity of these cells.

Keywords: Umbilical cord blood, Human hematopoietic stem/progenitor cells, Mesenchymal stromal cells, Bone marrow, Adipose tissue, Umbilical cord matrix, Ex vivo expansion

\section{Background}

Umbilical cord blood (UCB) has emerged as an alternative source of hematopoietic stem/progenitor cells (HSPC) for patients lacking a suitable donor in the context of allogeneic hematopoietic cell transplantation (HCT). Over the last two decades, the number of allogeneic HCT more than duplicated in the United States of America (USA). Considering unrelated donor allogeneic HCT only, the number of UCB transplants in adults peaked at $14 \%$ in 2010 but has been losing ground to the adult tissue sources of HSPC (mobilized peripheral blood and bone marrow (BM)) and accounted for $7 \%$ of the more than 5000 unrelated donor grafts performed in the USA in 2019 [1]. It is estimated that around 800,000 and 4 million UCB units are currently stored in public or private UCB banks, respectively, worldwide. This investment and development in UCB banking allowed a reduction in the searching time for unrelated donors, as compared to adult tissue sources [2]. Despite being a readily available source, with lower immunogenicity and lower risk of development of graft-vs-host disease (GVHD) compared to other sources, the low cell dose in a single UCB unit constitutes a major limitation [3]. In this context, the majority of HCT with UCB cells were initially limited to children weighing $20-40 \mathrm{~kg}$ [4]. To overcome the limitations of a low cell dose for transplantation of adult patients, two main strategies have been employed: (i) HCT using two unmanipulated UCB units (standard of care) [5] and (ii) HCT using two UCB units, one of which containing cells that were expanded ex vivo [6]. Several protocols were developed to promote ex vivo expansion of UCB HSPC, including the use of different media, cytokines, growth factors, and more recently the use of small molecules and chemical compounds [6-8]. Alongside these approaches, BM mesenchymal stromal cells (MSC) have been used in a co-culture system to support the ex vivo expansion and maintenance of HSPC. This strategy emerged to recapitulate the hematopoietic niche within the BM, where MSC have a pivotal role by giving structural support for HSPC to grow but also to influence their homing, stemness and differentiation potential [8]. Over the last years, we have studied the supportive capacity of BM MSC to UCB HSPC ex vivo in a co-culture setting [9-11] with a tailored cytokine cocktail recently established [12]. In a clinical setting, a significant improvement in neutrophil and platelet engraftment was observed in patients with hematologic cancers who received a unit of UCB previously expanded with BM MSC in addition to an unmanipulated UCB unit [13]. Co-transplantation of both BM MSC and UCB HSPC has also been employed in an $\mathrm{HCT}$ context with pediatric patients. Infusion of MSC proved to be safe, was associated with decreased incidence of acute GVHD, and consequently reduced transplant-related mortality [14, 15].

From a hematopoietic niche perspective, the use of BM MSC can be seen as the logical choice to establish a recreation of the microenvironment where HSPC reside in vivo. Despite the majority of studies employing human MSC use BM-derived cells [16], requiring an invasive procedure that entails risks to donors, MSC can also be efficiently isolated from other tissues [17]. Overall, adipose tissue (AT) and umbilical cord matrix (UCM) display advantages over BM as a source of MSC, namely ease of collection using minimally/non-invasive procedures. For instance, AT MSC, derived from the stromal vascular fraction (SVF) of AT, can be easily obtained through enzyme-based isolation procedures from subcutaneous AT [18], which is usually discarded as medical waste and offers the possibility of resampling. Interestingly, stromal cells in the SVF share similarities with those of the BM [19] and some studies have focused on the potential of these cells to support ex vivo expansion of UCB progenitors [20-22]. On the other hand, the umbilical cord tissue, specifically the Wharton's jelly or matrix (UCM), has been explored as a promising source of MSC [23]. Of notice, Wharton's jelly MSC has been recently proposed as a preferable feeder layer (FL) choice for UCB HSPC expansion ex vivo considering the microenvironment of the umbilical cord and placenta, where UCB hematopoietic progenitors reside in, which differs from the adult BM niche [24]. Although these alternative sources of MSC have been compared with the standard BM-derived MSC, namely focusing on identity criteria such as immunophenotype and multilineage differentiation potential $[25,26]$, a direct comparison among these tissue sources is still missing in what concerns 
their capacity to support the ex vivo expansion of UCB HSPC.

Regardless of the MSC source chosen for the coculture system, the main goal would be the development of a cost-effective, clinical-grade, co-culture system using serum-free (SF)/xenogeneic-free (XF) culture materials towards the maximization of cell yield, while increasing product consistency and maintaining product features [12]. Specifically, the translation of such system to an approved cell therapy product would certainly rely on two main parameters that are commonly evaluated in clinical trials: total nucleated cells (TNC) and percentage of $\mathrm{CD}_{4}{ }^{+}$cells. This is due to the fact that higher doses of TNC, as well as UCB units enriched with $\mathrm{CD} 34^{+}$cells, have been positively correlated with better clinical outcomes (namely, neutrophil engraftment) in patients receiving expanded UCB cells [6]. For single UCB transplantation, a minimum TNC dose of $\geq 2.5 \times 10^{7} / \mathrm{kg}$ and a minimum prefreeze $\mathrm{CD} 34^{+}$dose of $\geq 1.5 \times 10^{5} / \mathrm{kg}$ is desirable [27].

To fulfill the existing gap regarding the efficacy of using alternative sources to BM-derived MSC, we designed this study whose aim is to make a comprehensive comparison of the ex vivo expansion capacity of UCB $\mathrm{CD} 34^{+}$-enriched cells in a co-culture system using different sources of MSC, namely BM, AT, and UCM. In an attempt to establish a XF co-culture system, we also tested the feasibility of establishing FL of MSC from the different sources using medium supplemented with fibrinogen-depleted human platelet lysate (HPL), instead of fetal bovine serum (FBS). FBS is the most widely used serum-based supplement for the culture of eukaryotic cells in vitro, being rich in a variety of components, such as vitamins, hormones, transport proteins, and growth factors, that allows cell growth, maintenance, and proliferation in vitro. Although FBS raises issues related to safety (e.g., high endotoxin content, potential source of microbial contaminants and presence of xenogeneic serum antigens that can trigger severe immunological reactions) and animal welfare [28], it is still the most popular supplement used for MSC manufacturing, including at a clinical level [13]. Specifically, a phase III clinical trial with patients that received HSPC expanded ex vivo in a co-culture system with MSC previously cultured using FBS was recently completed (ClinicalTrials. gov Identifier: NCT01854567).

\section{Methods}

\section{Human samples}

Human samples were obtained from local hospitals (umbilical cord blood (UCB) and tissue: Hospital São Francisco Xavier, Centro Hospitalar de Lisboa Ocidental; bone marrow (BM): Instituto Português de Oncologia Francisco Gentil, Lisboa; Adipose tissue (AT): Clínica de
Todos-os-Santos, Lisboa) under collaboration agreements with Institute for Bioengineering and Biosciences, Instituto Superior Técnico (iBB-IST), after written and informed consent and according to the Directive 2004/ 23/EC of the European Parliament and of the Council of 31 March 2004 regarding standards of quality and safety for the donation, procurement, testing, processing, preservation, storage, and distribution of human tissues and cells (Portuguese Law 22/2007, June 29), with the approval of the Ethics Committee of the respective clinical institution. All samples used in this study were obtained from human donors (the mothers, in the case of UCB and tissue) that have previously tested negative for common virus and diseases.

\section{Preparation of human mesenchymal stromal cell (MSC)- feeder layers (FL)}

Cells from a single donor of each tissue source (BM, AT and UCM) were used to establish FL, mimicking an allogeneic universal donor for each source, as recently proposed by our group [12]. Human MSC were obtained from the Stem Cell Engineering Research Group (SCER G) cell bank, at iBB-IST, Lisboa, Portugal. These cells were previously isolated and expanded under normoxia conditions using fetal bovine serum (FBS)-supplemented medium, characterized and cryopreserved by our group according to established protocols [29]. Cells from all tissue sources used in this study have been previously shown to comply with International Society for Cell \& Gene Therapy (ISCT) criteria in what concerns identity and characterization of MSC (i.e., expression of CD73, CD90 and CD105; lack of expression of CD34, CD45, CD73, CD80, CD90, CD105, CD14 and HLA-DR and confirmation of tri-lineage differentiation potential) [30, 31]. Firstly, MSC were thawed and seeded using low glucose Dulbecco's Modified Eagle's Medium (DMEM) (Thermo Fisher Scientific, United States of America (USA)) supplemented with 10\% (v/v) MSC-qualified FBS (Thermo Fisher Scientific) (i.e., specially tested to support the expansion and clonal enumeration (MSC CFU$\mathrm{F}$ assay) of MSC). Then, in order to establish MSCbased FL under xenogeneic-free (XF) conditions, i.e., MSC expanded without FBS-containing medium, half of the cells were subjected to two adaptive passages with low glucose DMEM supplemented with $5 \%(\mathrm{v} / \mathrm{v})$ fibrinogen-depleted human platelet lysate (HPL) (Ultra$\mathrm{GRO}^{\mathrm{TM}}$-PURE; kindly provided by AventaCell Biomedical Corp., USA) (Certificate of Analysis (CoA) provided), while the other half continued to be expanded in low glucose DMEM with 10\% MSC-qualified FBS (both supplemented with $1 \% \quad(\mathrm{v} / \mathrm{v})$ AntibioticAntimycotic (A/A) (Gibco, USA)). MSC were seeded at 3000 cells $/ \mathrm{cm}^{2}$ into cell culture flasks and medium was changed every 3 days until $80-90 \%$ confluence was 
reached. After the two adaptive passages, MSC were seeded (in P5 or P6) onto wells of a 12-well plate using the appropriate medium. Once confluence was reached, MSC growth was arrested by using medium supplemented with $0.5 \mu \mathrm{g} / \mathrm{mL}$ (BM and AT MSC) [32] or $5 \mu \mathrm{g} /$ $\mathrm{mL}$ (UCM MSC) ([33]; unpublished results) Mitomycin$\mathrm{C}$ (Sigma-Aldrich, USA) for $2.5-3 \mathrm{~h}$ at $37{ }^{\circ} \mathrm{C}$ and $5 \%$ $\mathrm{CO}_{2}$. A higher concentration of Mitomycin-C was used for UCM MSC due to their higher in vitro proliferative capacity compared to their adult counterparts [23]. Mitomycin-C treated FL were carefully washed twice and kept with the respective medium at $37{ }^{\circ} \mathrm{C}$ and $5 \%$ $\mathrm{CO}_{2}$ for no more than $72 \mathrm{~h}$ until further co-culture with hematopoietic stem/progenitor cells (HSPC).

\section{Isolation of umbilical cord blood (UCB) mononuclear cells (MNC)}

MNC were isolated from fresh UCB samples through a Ficoll (GE Healthcare, USA) density gradient centrifugation. After washing with $2 \mathrm{mM}$ ethylenediamine tetraacetic acid (EDTA) (Sigma-Aldrich) in phosphatebuffered saline (PBS) (Sigma-Aldrich) and upon treatment with ammonium chloride $(155 \mathrm{mM})$ (Sigma-Aldrich) for $10 \mathrm{~min}$ at $4{ }^{\circ} \mathrm{C}$ to eliminate residual erythrocytes, MNC were cryopreserved using Recovery Cell Culture Freezing Medium (Gibco) and stored in a liquid/vapor phase nitrogen tank.

\section{Enrichment for $\mathrm{CD}_{3} 4^{+}$cells}

Cryopreserved MNC from three UCB samples were individually thawed in DMEM $+20 \%(\mathrm{v} / \mathrm{v}) \mathrm{FBS}$ and washed with magnetic-activated cell sorting (MACS) buffer. $\mathrm{CD}_{4}{ }^{+}$HSPC were then isolated using the CD34 MicroBead Kit UltraPure (Miltenyi Biotec, Germany) through MACS, according to the manufacturer's instructions. In order to attain a highly pure $\mathrm{CD}^{+} 4^{+}$cell population, cells from the positive fraction were subjected to a second LS MACS column.

\section{Ex vivo expansion of $\mathrm{CD} 34^{+}$-enriched cells}

CD34 ${ }^{+}$-enriched cells from UCB $(30,000 / \mathrm{mL})$ were resuspended in StemSpan SFEM II medium (STEMCELL Technologies, Canada) supplemented with $1 \%(\mathrm{v} / \mathrm{v}) \mathrm{A} / \mathrm{A}$ and SCF, TPO, FLT3-L, and bFGF cytokines (PeproTech, USA) (90, 77, 82 and $5 \mathrm{ng} / \mathrm{mL}$, respectively, for co-cultures with a MSC FL; and $64,80,61$, and $5 \mathrm{ng} / \mathrm{mL}$, respectively, for cultures without a MSC FL). Cytokine concentrations were previously optimized for these culture systems by our group [12]. Two milliliters of cell suspension was deposited in each well of a 12-well plate containing a MSC FL previously prepared as mentioned above (or under stroma-free conditions, i.e., no feeder layer (NO FL)) and expanded for 7 days at $37{ }^{\circ} \mathrm{C}$ and $5 \%$ $\mathrm{CO}_{2}$ in a humidified atmosphere (Fig. 1). At the end of the experiment, UCB total nucleated cell (TNC) count and viability were determined through the Trypan Blue (Gibco) exclusion method.

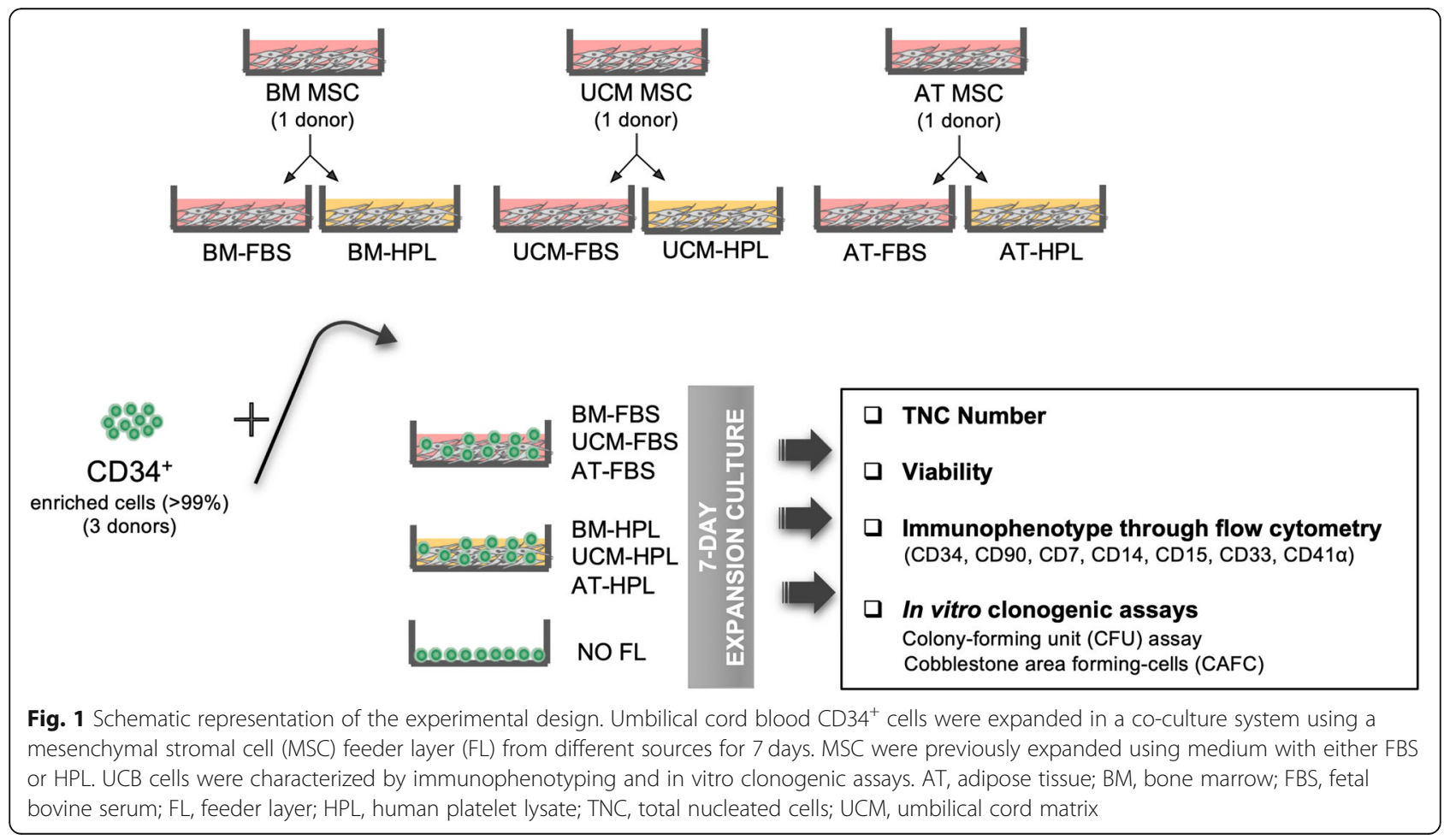


Immunophenotypic characterization

HSPC before and after expansion (days 0 and 7, respectively) were firstly incubated with Far Red LIVE/DEAD Fixable Dead Cell Stain Kit (Thermo Fisher Scientific) to assess cell viability and then surface stained with the following anti-human antibodies: CD34 (8G12) PerCPCy5.5, CD41 $\alpha$ (HIP8) PE (BD Pharmingen, USA); CD90 (5E10) PE, CD7 (CD7-6B7) FITC, CD14 (M5E2) FITC, CD15 (HI98) PE, and CD33 (WM53) PE (BioLegend, USA). Cells were acquired on a FACSCalibur flow cytometer (BD Biosciences, USA), and data was analyzed using FlowJo v10 software (FlowJo LLC, USA).

\section{In vitro clonogenic assays}

The ability of expanded and non-expanded hematopoietic progenitors to proliferate and differentiate was assessed through the colony-forming unit (CFU) assay. Briefly, 1000 (day 0) or 2500 (day 7) cells were resuspended in MethoCult H4434 Classic (STEMCELL Technologies) and seeded onto wells of a 24-well plate. After 14 days of incubation at $37{ }^{\circ} \mathrm{C}$ and $5 \% \mathrm{CO}_{2}$, formed colonies were counted using a bright-field microscope (Olympus CK40-F200, Japan) and classified as erythroid burst-forming unit (BFU-E), colony-forming unit granulocyte-monocyte (CFU-GM) or multilineage colony-forming unit (CFU-Mix). Colony number was normalized by the number of seeded cells and multiplied by the TNC number. Fold-increase (FI) of CFU was calculated dividing the number of colonies on day 7 by the number of colonies on day 0 .

Stemness of expanded and non-expanded cells was also assessed through the cobblestone area-forming cells (CAFC) assay. Two thousand cells were resuspended in MyeloCult ${ }^{\mathrm{mm}}$ medium (STEMCELL Technologies) supplemented with $350 \mathrm{ng} / \mathrm{mL}$ of hydrocortisone (STEMCELL Technologies), seeded on top of a growth-arrested FL of MS-5 cells on a 24 well-plate, in duplicates, and incubated for 14 days at $37{ }^{\circ} \mathrm{C}$ and $5 \% \mathrm{CO}_{2}$. CAFC were visualized using a phase-contrast microscope (Leica DMI3000 B, Germany) and registered if at least 5 cells with cobblestone-like morphology were able to migrate beneath the murine FL [34]. FI of CAFC was calculated dividing the number of CAFC on day 7 by the number of CAFC on day 0.

\section{Statistical analysis}

Statistical analysis was performed using SPSS Statistics v26 software (IBM, USA). Results are presented as mean \pm standard error of the mean (SEM). The Shapiro-Wilk test was carried out to assess normal distribution. Paired sample $t$ tests were conducted to compare differences between conditions. A p value $<0.05$ was considered statistically significant for all tests.

\section{Results}

Adipose tissue (AT) mesenchymal stromal cells (MSC) outperform umbilical cord matrix (UCM) MSC in promoting the ex vivo expansion of umbilical cord blood (UCB)-derived hematopoietic stem/progenitor cells (HSPC) At day 7 of culture, UCB-derived HSPC showed a high viability $(>90 \%)$ in all co-cultures tested using different MSC feeder layers (FL) (bone marrow (BM), AT and $\mathrm{UCM}$ ), as well as in cultures without a MSC FL (NO $\mathrm{FL})$. Fold increase (FI) in total nucleated cells (TNC) ranged from 50 to 83 (Fig. 2). Co-culture with AT and BM MSC resulted in the highest FI of TNC for UCB cells, with the former allowing slightly higher values (> 80 and $>70$, respectively). In the conditions of our study, UCM-derived MSC resulted in the lowest expansion of UCB cells, with FI TNC values similar to the negative control, i.e., HSPC expanded without a MSC FL. In particular, the expansion levels in TNC for UCB cells cocultured with a FL of UCM MSC previously established using either fetal bovine serum (FBS)- (UCM-FBS) or fibrinogen-depleted human platelet lysate (HPL)-supplemented medium (UCM-HPL) significantly differed $(p<$ 0.01 and $p<0.05$, respectively) from the FI values obtained with HSPC co-cultured with a FL of AT MSC previously established with FBS-supplemented medium (AT-FBS). Nevertheless, the culture medium in which MSC were previously expanded (FBS vs HPL supplementation) did not seem to have a major impact on the overall expansion of HSPC, as observed by the FI TNC values obtained.

\section{Tissue source of MSC and xenogeneic-free culture} conditions for the establishment of the FL influence the differentiative potential of UCB expanded cells

Through immunophenotypic characterization of the expanded and non-expanded UCB-derived HSPC, different dynamics were observed according to the culture medium in which MSC FL had been previously established (Fig. 3). At day 7, a CD34 ${ }^{+}$cell population was maintained in culture, which varied between 30.4 and $69.1 \%$ for the co-cultures, with the negative control (NO FL) presenting a population of $43.7 \pm 7.0 \%$. Regarding this $\mathrm{CD} 34^{+}$cell population, not only differences between the distinct MSC sources were observed, but also between MSC-FBS and MSC-HPL FL within the same source, with the former presenting a higher $\mathrm{CD} 34^{+}$cell content: $69.1 \pm 2.3 \%$ (BM-FBS) vs $56.2 \pm 0.8 \%$ (BMHPL) (p < 0.05); $45.4 \pm 2.9 \%$ (UCM-FBS) vs $30.4 \pm 3.2 \%$ (UCM-HPL) (p < 0.01); and $68.6 \pm 0.9 \%$ (AT-FBS) vs $56.1 \pm 2.2 \%$ (AT-HPL) $(\mathrm{p}=0.056)$ (Fig. 4a). In order to highlight the differences observed in what concerns CD34 expression by the expanded UCB in the different culture conditions, we performed a histogram overlay analysis (Fig. 5a). For all conditions tested, two peaks 


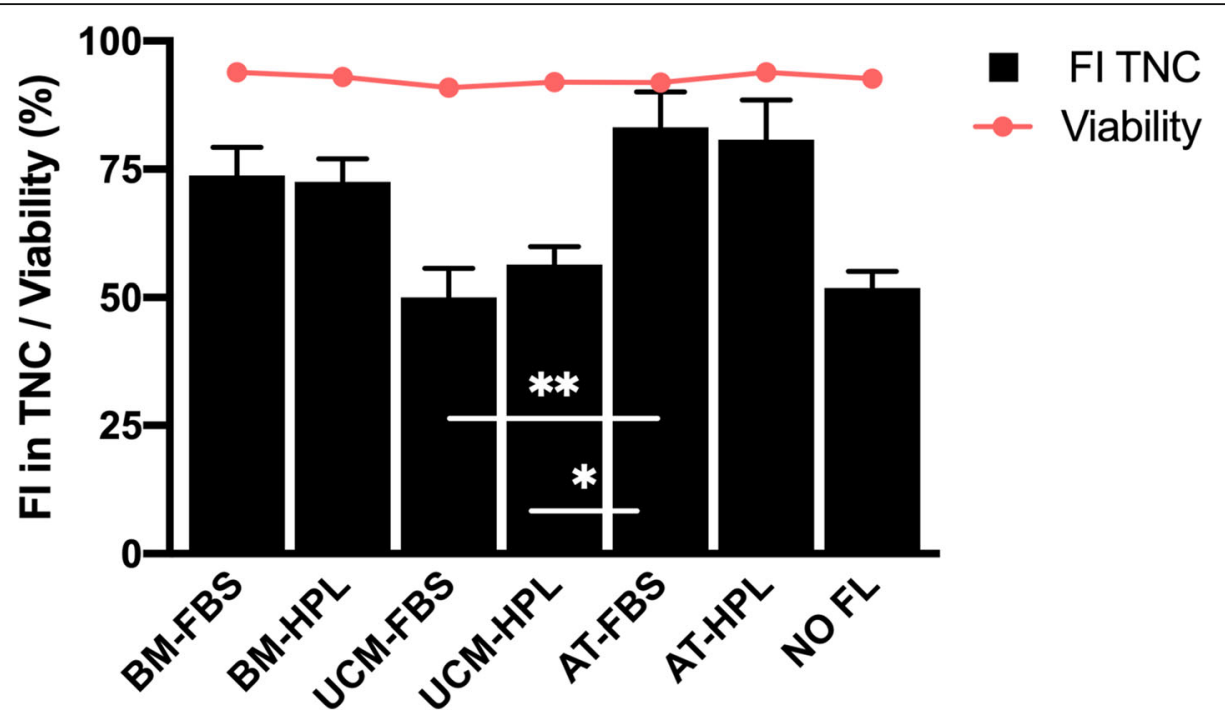

Fig. 2 Viability and fold increase in total nucleated cells of expanded umbilical cord blood-derived hematopoietic stem and progenitor cells after 7 days of co-culture with mesenchymal stromal cells from different sources. AT, adipose tissue; BM, bone marrow; FBS, fetal bovine serum; Fl, fold increase; FL, feeder layer; HPL, human platelet lysate; TNC, total nucleated cells; UCM, umbilical cord matrix. Values are presented as mean \pm SEM. $n=3$ for all conditions, with exception of 'NO FL': $n=2 .{ }^{* *} p<0.01 ;{ }^{*} p<0.05$

can be observed: one corresponding to $\mathrm{CD}^{+} 4^{+}$cells (positive peak) and the other to CD34- cells (negative peak). The positive peak (i.e., CD34 ${ }^{+}$cells) is notably higher and more pronounced for the conditions where BM-FBS and AT-FBS FL were used. For UCB cells expanded in BM-HPL and AT-HPL conditions, the positive peak is not as high or intense as observed for the FBS conditions. Concerning the UCB cells expanded with a FL of UCM MSC, the positive peak is the smallest of all co-cultures, being smaller and less intense for the UCM-HPL condition than the UCM-FBS condition, resembling the behavior observed with HSPC expanded under feeder-free conditions (NO FL). In order to depict the more primitive stem/progenitor content of the UCB HSPC after culture, the immunophenotypic analysis included the assessment of CD34 and CD90 surface markers, as the subpopulation containing more primitive cells is characterized by its simultaneous expression (i.e.,

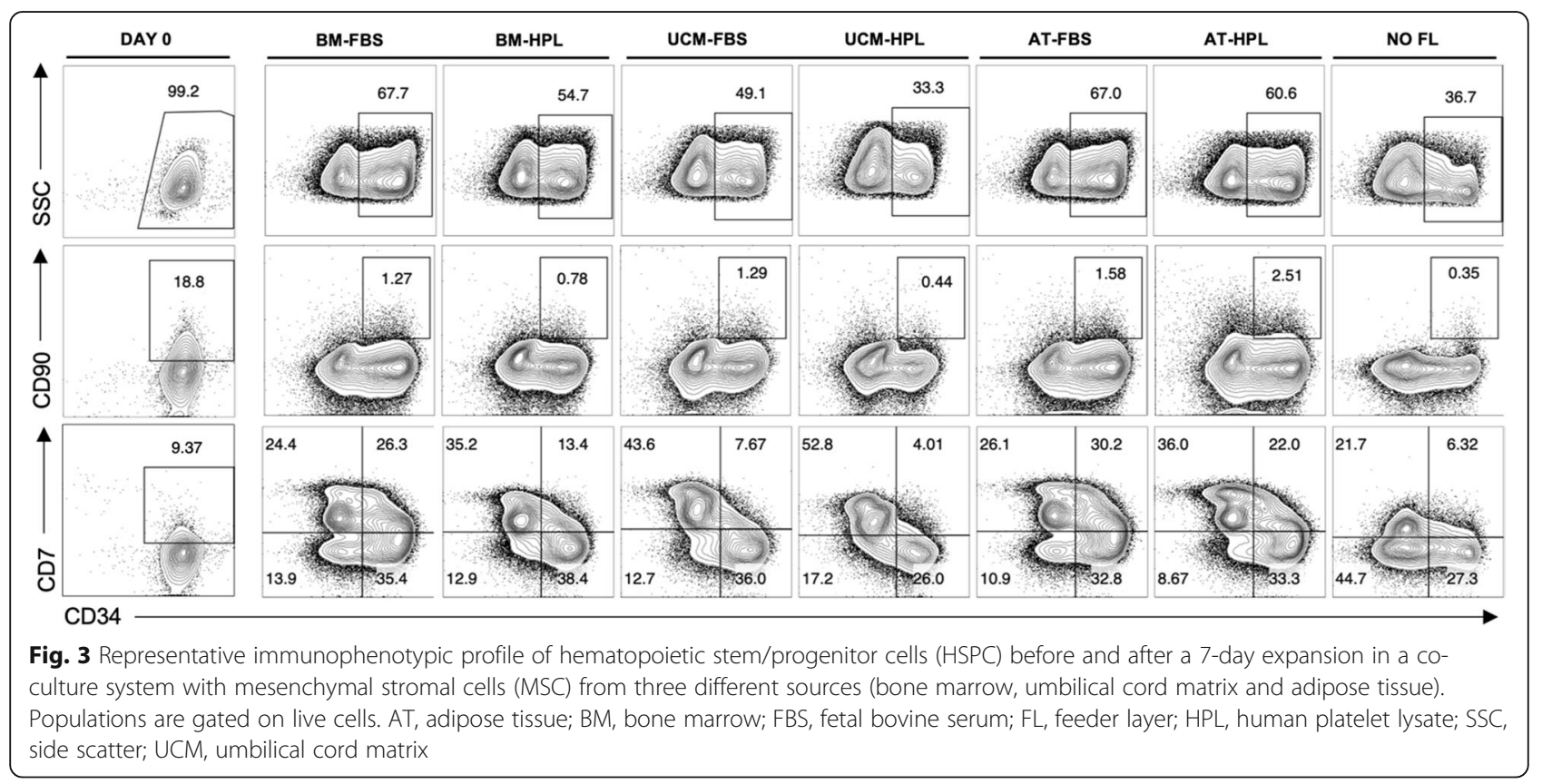




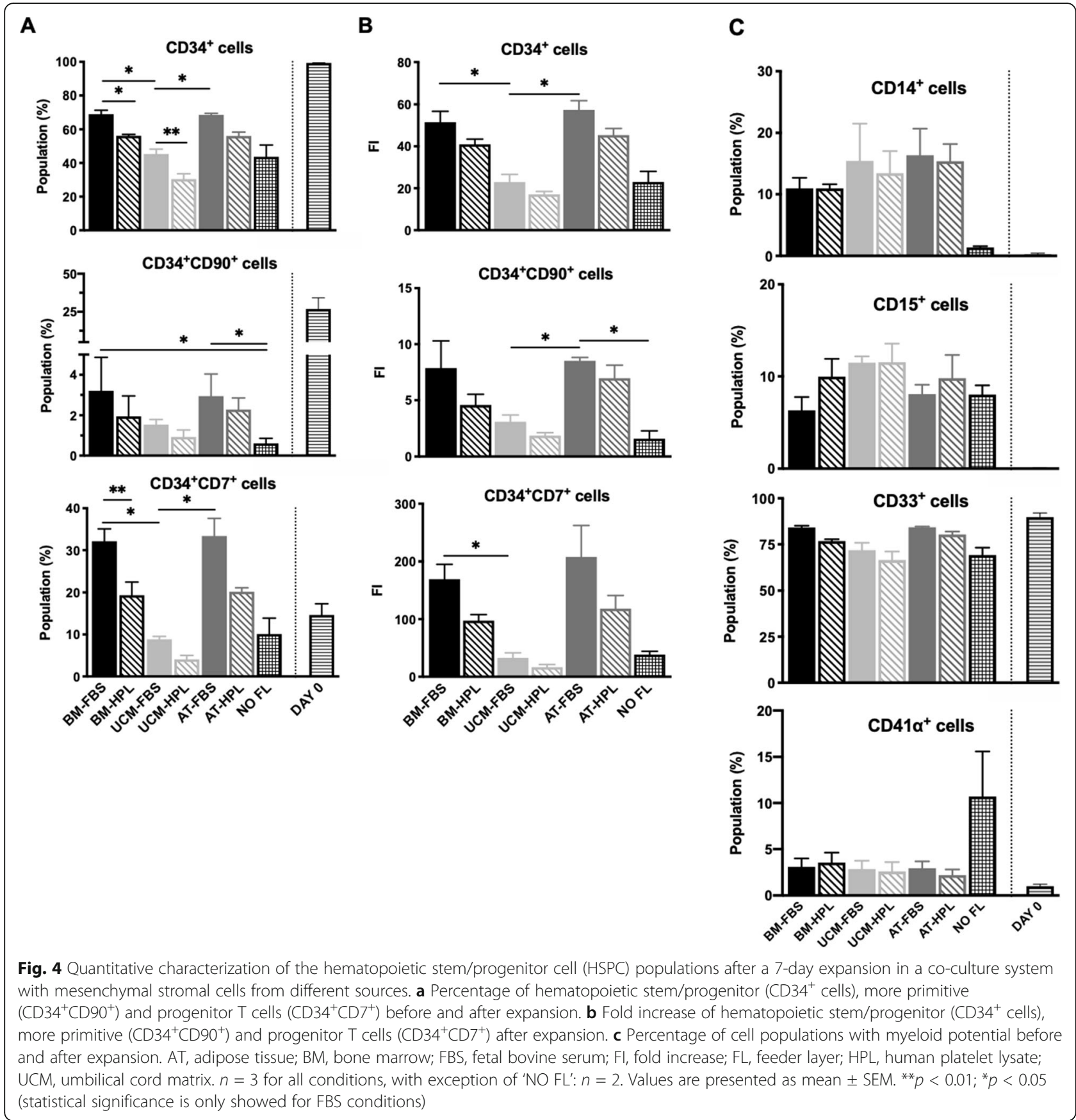

$\mathrm{CD} 4^{+} \mathrm{CD}^{+} 0^{+}$cells). While BM and AT FL were able to maintain a similar percentage of this specific subpopulation of more primitive UCB HSPC, the UCM FL seems to have yielded a smaller percentage. Nonetheless, for all MSC sources studied, the percentage of this subpopulation showed a tendency to be inferior when MSC-HPL were used in the co-culture system: $3.2 \pm 1.7 \%$ (BMFBS) vs $2.0 \pm 1.0 \%$ (BM-HPL); $2.9 \pm 1.1 \%$ (AT-FBS) vs $2.3 \pm 0.6 \%(\mathrm{AT}-\mathrm{HPL}) ; 1.5 \pm 0.3 \%$ (UCM-FBS) vs $0.9 \pm$ $0.3 \%$ (UCM-HPL); and $0.6 \pm 0.3 \%$ (NO FL). Another subpopulation of interest that was assessed were the
proT cells (i.e., progenitor $\mathrm{T}$ cells), defined as cells that co-express the surface markers CD34 and CD7 (i.e., $\mathrm{CD} 34^{+} \mathrm{CD}^{+}$cells). For the proT cell subpopulation, the immunophenotypic analysis showed the same pattern observed in the subpopulation containing more primitive cells. Of notice, the difference between HPL and FBS conditions is also evident for the proT cell subpopulation, as UCB HSPC that were co-cultured with BM-FBS resulted in an increase of more than $50 \%$ on the expression of both CD34 and CD7 markers, when compared to BM-HPL: $32.1 \pm 2.9 \%$ vs $19.3 \pm 3.2 \%$ (p < 0.01). Co- 
A

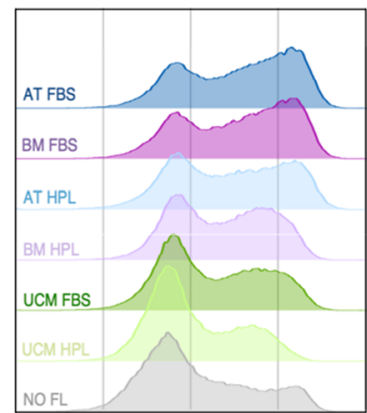

B

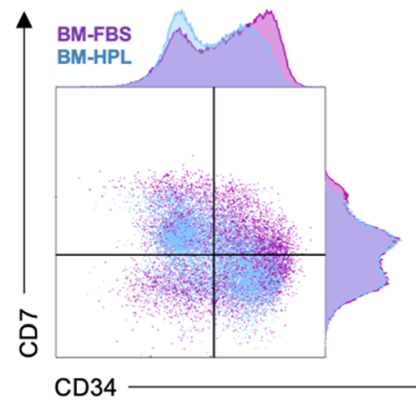

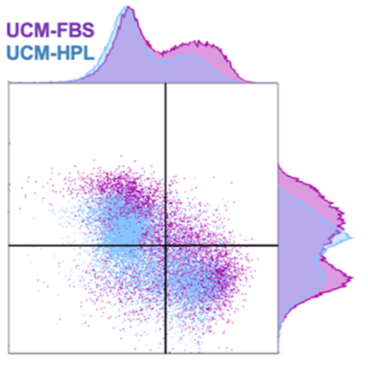

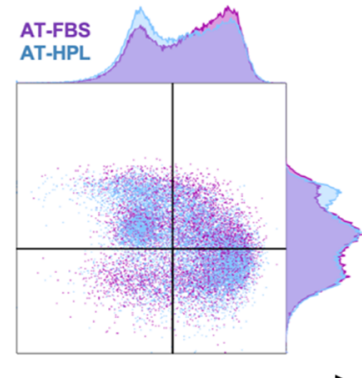

Fig. 5 Comparison of CD34 and CD34/CD7 expression by expanded umbilical cord blood (UCB) cells after 7 days of co-culture with mesenchymal stromal cells (MSC) from different sources previously established using different medium supplementation (fetal bovine (FBS) or human platelet lysate (HPL)). a Histogram overlay of CD34 expression by expanded UCB cells co-cultured with MSC feeder layers from different tissue sources that were previously established with FBS- or HPL-supplemented medium (representative UCB donor). b Dot plot overlay of CD34 and CD7 Coexpression by expanded UCB cells co-cultured with MSC feeder layers from the same tissue source that were previously established with FBS- or HPL-supplemented medium (representative UCB donor). AT, adipose tissue; BM, bone marrow; FBS, fetal bovine serum; HPL, human platelet lysate; UCM, umbilical cord matrix

cultures using the other MSC sources followed the same tendency: $33.4 \pm 4.2 \%$ (AT-FBS) vs $20.2 \pm 1.0 \%$ (ATHPL); $8.9 \pm 0.7 \%$ (UCM-FBS) vs $4.1 \pm 0.9 \%$ (UCMHPL); and $10.1 \pm 3.8 \%$ (NO FL) (Fig. 4a; Fig. 5b). Expansion levels of the aforementioned subpopulations $\left(\mathrm{CD} 34^{+}, \mathrm{CD} 34^{+} \mathrm{CD} 90^{+}\right.$and $\left.\mathrm{CD} 34^{+} \mathrm{CD} 7^{+}\right)$, expressed as FI, followed the tendency observed for cell population content (in percentage) (Fig. $4 \mathrm{~b}$ ).

In all cultures, the differentiative potential of the expanded UCB cells was mainly shifted towards the myeloid lineage (Fig. 4c). A high expression of CD33, a myeloid-specific receptor, was observed on nonexpanded cells (day 0), but also on expanded cells regardless of the MSC source used in the co-culture system, as well as on the control without FL. Nonetheless, UCB cells expanded over MSC-HPL seem to show a slight decrease of this marker compared to MSC-FBS conditions. CD14 ${ }^{+}$cells (monocytic potential) were also present on day 7 (11.0-16.4\%), without any obvious differences between UCB cells expanded over MSC-FBS or MSC-HPL within each MSC source. On the other hand, UCB cells expanded without FL showed a residual population with monocytic potential $(1.3 \pm 0.2 \%)$. Conversely, hematopoietic cells expanded under feeder-free conditions (NO FL) displayed a considerable population $(10.7 \pm 4.9 \%)$ of $\mathrm{CD} 41 \alpha^{+}$cells (megakaryocytic potential) whereas the $\mathrm{CD} 41 \alpha^{+}$population varied between 2.2 and $3.5 \%$ in the co-cultures. $\mathrm{CD}^{+} 5^{+}$cells (granulocytic potential) were also present among the expanded UCB cells and its percentage varied according to the MSC source used to establish the FL (6.3-11.5\%), with no evident influence of culture medium used; UCB cells expanded under feeder-free conditions (control) comprised a population of $8.0 \pm 1.0 \% \mathrm{CD} 15^{+}$cells.
UCB expanded cells maintain their clonogenic potential regardless of the MSC tissue source and culture conditions

Besides immunophenotyping, we performed two different assays to identify the presence of primitive cells and the clonogenic potential of the progenitor cells: the cobblestone area-forming cells (CAFC) assay and the colony-forming unit (CFU) assay, respectively. By using our co-culture expansion system, we verified that, regardless of the MSC source used to expand the UCB cells, all of them allowed a FI in the number of CAFC of expanded UCB cells (Fig. 6a). There seemed to a be a tendency for a FL of BM or AT MSC to allow for a slight increase in the FI, as the mean ranged from 3.4 to 6.3, while the mean FI of CAFC of the expanded cells ranged between 2.4-3.1 when a FL of UCM MSC was used. However, no statistical significance was found among MSC sources. UCB cells expanded without a FL (NO FL) presented the smallest mean FI of CAFC (1.1 \pm 1.1).

Regarding the clonogenic potential, assessed through the CFU assay, as expected, the number of total CFU obtained per $10^{5}$ HSPC was superior for UCB cells before expansion, on day $0\left(2.5 \times 10^{4} \pm 1.0 \times 10^{3}\right)$, than after expansion (Fig. 6b). After the 7-day expansion in the coculture system, even though the CFU values obtained with BM-MSC and UCM-MSC slightly differed between them, overall the number of total CFU was similar for UCB cells expanded in any of the MSC sources, ranging from $1.2 \times 10^{4} \pm 1.9 \times 10^{3}$ (UCM-HPL condition) to 1.5 $\times 10^{4} \pm 1.2 \times 10^{3}$ (BM-FBS condition). The culture medium in which MSC were established did not seem to have impact on the CFU total number produced by the UCB cells. Interestingly, cells expanded without a MSC FL (NO FL) seemed to show a higher number of total 


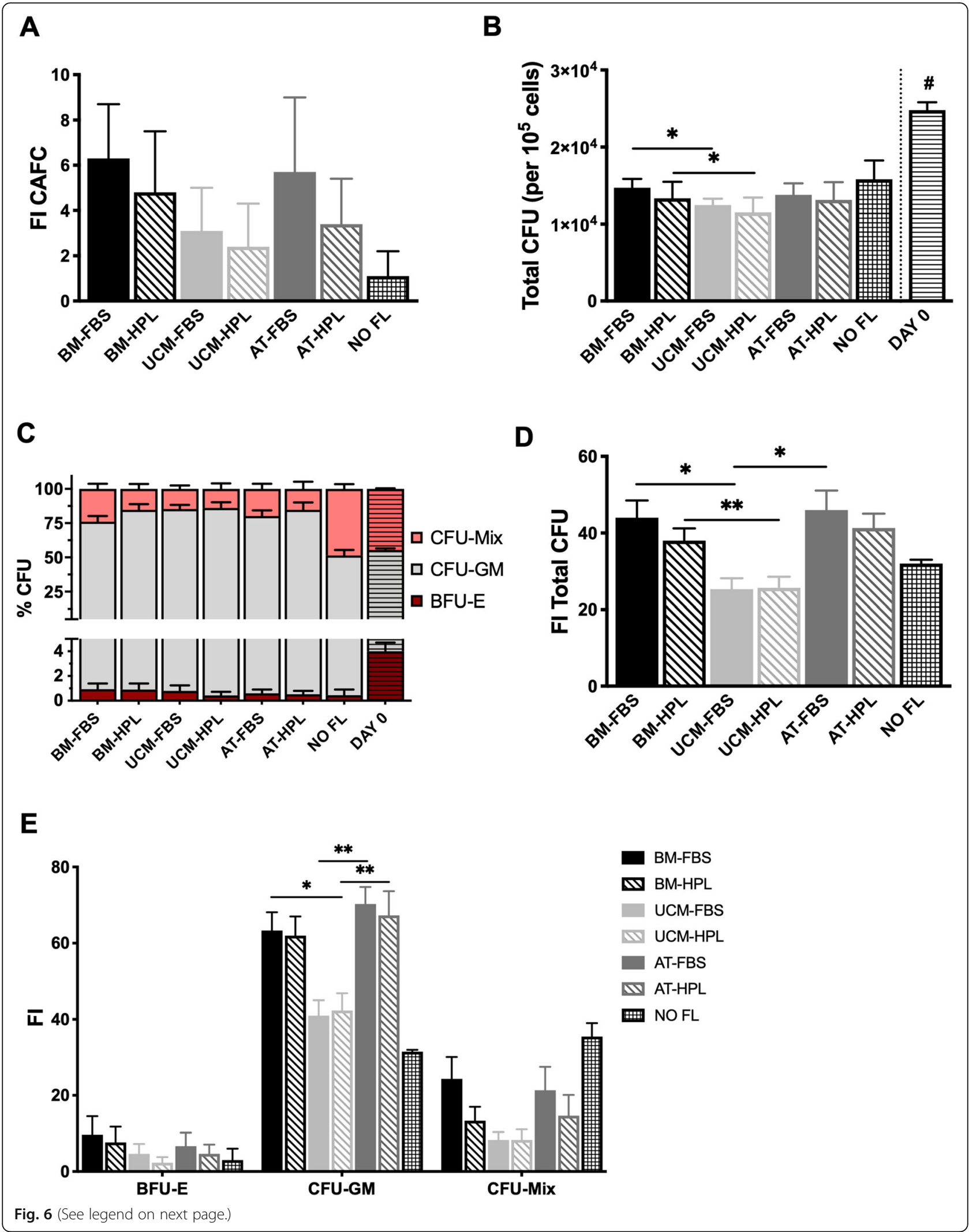


(See figure on previous page.)

Fig. 6 Cobblestone area-forming cells (CAFC) and colony-forming unit (CFU) produced by hematopoietic stem/progenitor cells (HSPC) before and after a 7-day expansion in a co-culture system with mesenchymal stromal cells (MSC) from different sources. a Fold increase of CAFC. b Total CFU obtained per $10^{5}$ UCB cells. c Percentage of each CFU type (BFU-E, CFU-GM, CFU-Mix) produced. d Fold increase of total CFU. e Fold increase of each CFU type (BFU-E, CFU-GM, CFU-Mix). AT, adipose tissue; BFU-E, erythroid burst-forming unit; BM, bone marrow; CFU-GM, colonyforming unit granulocyte-monocyte; CFU-Mix, multilineage colony-forming unit; FBS, fetal bovine serum; Fl, fold increase; FL, feeder layer; HPL, human platelet lysate; UCM, umbilical cord matrix. $n=3$ for all conditions, with exception of 'NO FL': $n=2$. Values are presented as mean \pm SEM ${ }^{* *} p<0.01 ;{ }^{*} p<0.05 ; \# p<0.01$ vs BM-FBS, UCM-FBS, UCM-HPL, AT-FBS and $p<0.05$ vs BM-HPL, AT-HPL

CFU $\left(1.6 \times 10^{4} \pm 2.5 \times 10^{3}\right)$ than the ones expanded with a MSC FL. We also looked in detail to the type of CFU produced (Fig. 6c), namely erythroid burst-forming unit (BFU-E), colony-forming unit granulocytemonocyte (CFU-GM) or multilineage colony-forming unit (CFU-Mix). For non-expanded cells (UCB cells on day 0 ), we verified that half of the colonies presented were committed to the myeloid lineage, as $51.5 \pm 0.5 \%$ of the colonies were CFU-GM, but there was also some erythroid potential, seen not only by the percentage of BFU-E $(4.0 \pm 0.7 \%)$ but also CFU-Mix (44.5 $\pm 0.5 \%)$. For the UCB cells expanded in a co-culture system, regardless of the MSC source used, we observed a shift in the type of colonies produced, as the great majority (> 70\%) were CFU-GM colonies. The erythroid potential was reduced, as less than $1 \%$ of the colonies were BFU-E, with the remaining colonies being CFU-Mix. Interestingly, for the conditions where UCB cells were expanded with MSC-HPL, the percentage of CFU-GM colonies showed a tendency to be slightly greater when compared with MSC-FBS conditions: $83.8 \pm 4,1 \%$ (BM-HPL) vs $75.1 \pm$ $4.1 \%$ (BM-FBS) and $84.2 \pm 5.5 \%$ (AT-HPL) vs $79.6 \pm$ $4.1 \%$ (AT-FBS). For the UCM MSC source, similar results were found $85.7 \pm 4.1 \%$ (UCM-HPL) vs $84.5 \pm 3.0 \%$ (UCM-FBS). Of notice, UCB cells that were expanded with NO FL presented percentages of CFU-GM and CFU-Mix very similar to the non-expanded cells on day 0 , with a reduction in the percentage of BFU-E.

In terms of FI of total CFU, which considers the aforementioned results and the expansion potential of our expansion systems, we verified that it follows the pattern observed for FI in TNC (Fig. 2). Specifically, UCB cells expanded over a FL of BM or AT MSC presented the highest FI in total CFU ( 40x), while the results obtained with a FL of UCM MSC were significantly lower $(\sim 25 \mathrm{x})$. No significant differences were observed regarding the establishment of the MSC sources with FBS- or HPL-supplementation (Fig. 6d). The influence of the MSC source on the expansion potential of UCB cells in what concerns each CFU type (BFU-E, CFU-GM, CFUMix) obtained was also explored (Fig. 6e). In co-cultures with MSC, the highest FI was observed for the CFUGM, followed by the CFU-Mix and lastly the BFU-E. Although with small differences, BM and AT MSC FL resulted in similar FI of each CFU type for the expanded
UCB cells, higher than the ones obtained with UCM MSC. Regarding the culture medium used in the MSC expansion, no influence in the FI of each CFU type seems to exist. On the other hand, expansion of HSPC without a MSC FL allowed for a substantial FI of CFUMix, which was very similar with the FI of CFU-GM, in opposition to what was observed for the MSC conditions.

\section{Discussion}

Wide application of umbilical cord blood (UCB) hematopoietic stem/progenitor cells (HSPC) to treat malignant and non-malignant diseases in a hematological context, specifically adult patients, is hampered by the low cell quantity in a single unit. While great efforts are being made to overcome this hurdle, expanding UCB HSPC ex vivo with the support of a bone marrow (BM) mesenchymal stromal cell (MSC) feeder layer (FL) is a relevant and commonly used strategy. Indeed, in 2012, the results of a phase I/II clinical trial where 31 patients with hematologic cancers received transplants of two UCB units, one of which containing HSPC expanded ex vivo in a co-culture system with BM MSC, were published [13]. Since transplantation of both UCB units proved to be safe and effective, significantly improving the engraftment compared to unmanipulated UCB only, the study moved to a phase III clinical trial. The study is now completed, but the results were not yet published (ClinicalTrials.gov Identifier: NCT01854567). Despite the encouragement and great advances that these clinical trials present to the field, they also mirror the need for optimization of these co-culture systems. Culture period is one of the topics that should be optimized. By doing a 2-week expansion of the UCB cells in the co-culture system with MSC, a medium change over the first week is demanded, which entails a superior cost of reagents, time, and handling. Our expansion protocol was designed to last one week without any media changes or handling in between, making it a more efficient system. Additionally, our expansion system, originally established with BM MSC, has its cytokine cocktail optimized for the maximum expansion without compromising the maintenance of HSPC [12], reducing overall cost of goods. Regarding the two main outputs evaluated in the translation of an expansion protocol to a clinical trial, 
i.e., the fold increase (FI) of total nucleated cells (TNC) and $\mathrm{CD} 34^{+}$cells, the authors were able to reach a FI of 12.2 in TNC, while the $\mathrm{CD} 34^{+}$cell fraction had a FI of 30.1 , after 14 days. In our study, by using a BM MSC FL in co-culture with the UCB HSPC, we were able to obtain a FI of 73.8 and 51.5, respectively, after 7 days. This increase can easily be explained not only by our optimized co-culture system, but also due to the starting cell product: in this clinical trial [13] mononucleated UCB cells were used, while we started with a highly purified population of UCB CD $34^{+}$cells.

In this clinical trial, off-the-shelf BM-derived MSC isolated using fetal bovine serum (FBS) were used to prepare the FL for the co-culture system. However, MSC isolated from the BM present some disadvantages related to the source per se, since BM collection is a very invasive procedure that entails risks for the donors. In addition, BM collection is not done as frequently as peripheral blood stem cell mobilization and collection, thus decreasing the availability of this source. While the majority of expansion studies use BM MSC derived from the iliac crest of the hip bone (from HSPC donors in a hematopoietic cell transplantation (HCT) context), BM samples can also be obtained from routine bone surgeries, namely from knee surgery. However, these medical interventions are normally associated with elderly patients, and it is well known that a decrease in MSC functionality, as well as in the number of passages they are able to withstand, is correlated with an increase in donor age [35]. Thus, although hematopoiesis occurs in the $\mathrm{BM}$ and from the physiological point of view the use of BM MSC would be the rational choice, alternative sources are required to ease clinical translation. Fortunately, there are other sources of MSC readily available, namely adipose tissue (AT) and umbilical cord matrix (UCM), which are commonly discarded as medical waste. Either of these MSC sources can be collected to isolate off-the-shelf MSC, in a similar way to what is done with BM-derived MSC. Direct comparison of using MSC from different sources, namely BM, UCM, and AT, have already been explored in different areas, such as treatment of graft-vs-host disease (GVHD) [36] and immune cell suppression capacity [37]. However, to our best knowledge, no study has performed a comprehensive comparison of the hematopoietic support provided by different sources of MSC to an enriched population of UCB HSPC.

In our study, we directly compared how three different sources of MSC-BM, UCM, and AT-influenced the expansion of UCB-derived $\mathrm{CD}^{+} 4^{+}$cells. This highly enriched population was isolated from cryopreserved mononuclear cells (MNC) of UCB samples. By using cryopreserved samples, we are replicating what is nowadays commonly performed in a clinical setting, since
UCB transplants are routinely performed with cryopreserved UCB units. Moreover, since the goal is to create an expansion product that can surpass the cell number issue of a single unit, studies than can achieve so by using cryopreserved samples are closer to reality. Additionally, we went further by exploring a serum-free (SF)/xenogeneic-free (XF) co-culture system, i.e., we compared the expansion capacity and cell profile of expanded UCB cells over a MSC FL previously established using either FBS or fibrinogen-depleted human platelet lysate (HPL).

By using a FL of MSC that were previously expanded in culture medium supplemented with FBS (BM-FBS, UCM-FBS, AT-FBS) in our co-culture systems, we were able to verify that after seven days of expansion a FI TNC of more than 70 or 80 for BM and AT, respectively, was achieved. Although one could speculate that the tendency for a higher expansion capacity obtained with AT would be accompanied by a loss of hematopoietic progenitors, the immunophenotypic analysis showed the maintenance of a high population (> $65 \%)$ of hematopoietic progenitors $\left(\mathrm{CD}_{4} 4^{+}\right.$cells) for both BM and AT sources. Concerning the fraction of expanded hematopoietic cells that suffered a loss of their CD34 expression, a shift towards the myeloid lineage was primarily observed (i.e., expression of CD14, CD15, $\mathrm{CD} 33$ and $\mathrm{CD} 41 \alpha$ ), as previously described by our group [10]. This behavior was substantiated by a higher percentage of CFU-GM in the co-culture system, regardless of the MSC FL source used. The absence of a FL during ex vivo expansion originated similar percentages of CFU-Mix and CFU-GM. This disparity regarding different CFU populations between expansion systems with and without a MSC FL has been previously observed by our group [12]. Interestingly, a small population that contains more primitive cells $\left(\mathrm{CD} 34^{+} \mathrm{CD} 90^{+}\right.$cells) [38] was also kept in both BM-FBS and AT-FBS conditions, which is aligned with the tendency for higher CAFCproducing capacity observed for these conditions. The CAFC assay is a variant of the long-term cultureinitiating cells (LTC-IC) assay that does not require cell replating. In our study, it was used to characterize the more primitive compartment of our expanded HSPC population, as this in vitro assay has been proposed as a valid surrogate measurement of hematopoietic reconstitution potential [39]. Our expansion protocol also expanded a particular subpopulation of progenitors that simultaneously express CD34 and CD7, classically defined as proT cells, i.e., progenitor cells with ability to homing the thymus and differentiate into $\mathrm{T}$ cells [40]. The expansion of this particular subpopulation is very promising, because not only the myeloid progenitors are being expanded in our co-culture system (as in most ex vivo expansion protocols), but also these precursors 
of the lymphoid lineage, which are candidates for adoptive $\mathrm{T}$ cell therapies [41]. Also, the significant presence of proT cells in our expanded population pool will contribute towards improving the recovery of a potential HCT patient, who inevitably is immunocompromised after treatment. An expanded product with such progenitors capable of a faster lymphopoiesis is critical to reduce HCT-related mortality [42, 43]. Both BM-FBS and AT-FBS FL allowed a percentage doubling for this particular UCB cell population after the expansion protocol. Importantly, and as seen in our previous work of 2010 [10], the presence of a MSC FL showed to be essential for the expansion of proT cells, as in the feeder-free system the percentage of this population was inferior to non-expanded cells. Of note, a population of CD $34^{-} \mathrm{CD}^{+}$cells was also present and expanded using any of the MSC FL. While this expanded population can be differentiated into natural killer and dendritic cells [44] that can be used in cellular immunotherapy, a small percentage of this population has been reported to be able to engraft the thymus in vivo [40], resulting in a broader redefinition of proT cells and suggesting that this population in our expansion system can also be of interest. On the other hand, using a UCM-FBS FL resulted in a lower FI TNC (50) that was also accompanied by a decrease in the progenitor populations seen through $\mathrm{CD}_{4} 4^{+}$expression $(<50 \%)$. Understandably, this decrease in the progenitor populations is also reflected on specific subpopulations, such as proT cells. Although present, the percentage of this population was smaller than before expansion. Compared to the adult sources, UCM MSC appear to provide less hematopoietic support in the conditions of our study, shown by the reduced expansion capacity and also progenitor population maintenance. Of notice, UCM MSC FL were subjected to a higher Mitomycin-C concentration in the growth-arrest treatment compared to their adult counterparts (5 vs $0.5 \mu \mathrm{g} / \mathrm{mL}$ ) due to the higher in vitro proliferation capacity of these cells [23]. Mitomycin-C has been commonly employed to inhibit MSC proliferation, as an alternative to irradiation, for multiple assays (e.g., immunomodulatory [45-47], FL for embryonic stem cells [48], induced pluripotent stem cells [49], as well as for HSPC $[50,51])$, and the concentration used varies in a $0.5-$ $50 \mu \mathrm{g} / \mathrm{mL}$ range. Importantly, it has been previously acknowledged that different cells might present an intrinsic sensitivity to this antibiotic and thus a dose-response curve to this agent has to be established for each cell type of interest [52]. In this context, a previous study demonstrated the higher efficiency of using MitomycinC concentrations of $4-8 \mu \mathrm{g} / \mathrm{mL}$ compared to a $0-2 \mu \mathrm{g} /$ $\mathrm{mL}$ range to growth-arrest human UCM MSC in vitro [33]. Although a possible influence of Mitomycin-C cannot be ruled out, the lower performance of UCM MSC
FL in supporting UCB HSPC observed in our study follows the trend present in the field. Other groups have demonstrated an inferior hematopoietic support associated to UCM MSC FL, which was shown using Mitomycin-C-treated [50, 51], irradiated [53], and noninactivated [54] FL.

Despite the fact that MSC have been mostly cultured with FBS-containing media in clinical trials, the risks associated with the usage of this culture medium supplement are well known, namely the risk of xenoimmunization against bovine antigens and the transmission of pathogens. Ethical issues associated with FBS collection, limited availability, and batch-to-batch variability are also concerns to be considered [28]. In the 1980s, HPL successfully started to be used as an alternative to FBS in the culture of several cell lines and is currently used in the manufacturing of MSC for clinical trials [55, 56]. This supplement is rich in potent bioactive mediators, including various chemokines and growth factors [57]. Current HPL formulations are fibrinogen-depleted (not requiring porcine heparin supplementation) and can be gamma irradiated to reduce pathogen content, which highly reduces the risk of transmission of human diseases by known or unknown viruses. In an attempt to make a product more closely available for clinical purposes, we decided to also establish a MSC FL expanded without the use of animal derived components, by using medium supplemented with fibrinogen-depleted HPL. Interestingly, we noticed that the expansion capacity of HSPC was not affected by the change of MSC expansion medium, as the FI TNC was similar for both FBS and HPL conditions within each source. However, a significant decrease in the percentage of $\mathrm{CD}^{+} 4^{+}$cells between FBS/HPL conditions within each MSC source was observed for all MSC sources, suggesting a shift from hematopoietic progenitors to more differentiated cells when MSC were expanded with HPL. It is worth mentioning that all differences observed resulted from an adaptation process, as MSC had been isolated with medium supplemented with FBS and first expanded with this medium. Interestingly, previous studies have reported that although HPL-supplemented medium improved the proliferation capacity of MSC in expansion, their immunosuppressive properties were inhibited in comparison to MSC expanded with FBS-supplemented medium. Namely, MSC expanded with fibrinogen-rich HPL showed a reduced capacity to prevent T- and NKcell proliferation $[58,59]$. Importantly, another study has shown that fibrinogen depletion from HPL can partially restore MSC immunomodulatory capacities [60]. Here, we could verify that the hematopoietic support provided by MSC can be modulated by the environment in which MSC grow and the source itself is not the only important factor. Considering our results and the absence of 
comparative studies concerning the hematopoietic supportive capacity of MSC cultured with HPL, further studies are needed.

Few studies exploring the hematopoietic support given by a FL of AT MSC exist. Without using exogenous cytokines, comparable levels of UCB HSPC expansion were attained when using a BM MSC FL or an AT MSC FL. Curiously, $\mathrm{CD}^{+}$cell percentage was significantly higher using the AT FL, while the $\mathrm{CD}^{+} 4^{+}$cell percentage was significantly enhanced using a BM FL [20]. Compared to BM MSC FL, a FL of AT MSC, either from mice or human, favored granulocyte differentiation from peripheral blood stem cells $\left(\mathrm{CD} 34^{+}\right.$cells) and the growth of progenitor cells in vitro to a higher extent. It was suggested that this better support could be attributed to chemokine CXCL12, a critical regulator of hematopoiesis, found to be expressed threefold higher in AT MSC than BM MSC [61, 62], even though less than $1 \%$ of genes were found to be differentially expressed between AT and BM MSC [63]. By seeding UCB MNC upon an AT MSC FL and making successive removals of nonadherent cells, Andreeva and colleagues [64] were able to verify that AT MSC enabled the selection of functionally active CD34 $4^{+} \mathrm{HSPC}$ at normoxia $\left(20 \% \mathrm{O}_{2}\right)$ and hypoxia levels $\left(5 \% \mathrm{O}_{2}\right)$ after 7 days of expansion. Even though they used an interesting strategy to enrich $\mathrm{CD} 4^{+}$cells during culture, their expansion levels were quite low (6-10x) compared to our FI of $\mathrm{CD} 34^{+}$cells (60x), which can easily be explained by their lack of exogenous cytokines besides using an expansion system that still relies on FBS usage.

UCM MSC, namely Wharton's jelly MSC, have also been studied regarding hematopoietic support to UCB $\mathrm{CD}_{3}{ }^{+}$cells. In order to simulate the growth of HSPC in vivo, Zhao and collaborators [24] studied the influence of oxygen percentage in the co-culture system without adding any cytokines, finding out that normoxia values enhanced FI of TNC (3x), CD34 $4^{+}$cells and CFU. Although hypoxia levels of $1 \% \mathrm{O}_{2}$ did not allow the expansion of TNC, they were able to maintain a higher percentage of $\mathrm{CD}_{3} 4^{+}$cells. By changing the expansion medium from $\mathrm{H} 5100$ medium to StemSpan medium supplemented with SCF, FLT3-L, and TPO cytokines, this group attained a higher FI in TNC (>300x), as well as in $\mathrm{CD} 4^{+}$cells (90x) [65]. Although similar to our coculture system, we were able to maintain a higher percentage of $\mathrm{CD}_{3} 4^{+}$cell population, despite the lower FI in this population. Nevertheless, these differences could be explained by their higher period of expansion (10 days). When Klein and colleagues [54] directly compared MSC from amnion, chorion, and Wharton's jelly to BM MSC, they verified that a FL of the latter source was significantly superior in expanding UCB CD34 $4^{+}$cells. Although their approach was different, as they started the expansion with unfractioned MNC cultured in medium supplemented with FBS over 14 days, BM MSC were shown to be a better source over UCM MSC, which is coherent with our results.

Overall, HSPC ex vivo expansion through co-culture with MSC can be influenced by multiple experimental variables. Whether by using different expansion media, oxygen levels or starting HSPC population, as well as usage of exogenous cytokines, the resulting expansion outcome will inevitably vary. While MSC donor variability could also be considered an important experimental parameter, its impact on the robustness of co-culture HSPC expansions can be controlled. Similar to the manufacturing model for Alofisel, an approved expanded AT MSC-based cell therapy, we expect that a cell bank produced from a single donor will be able to provide innumerous cell doses for MSC FL production. Additionally, by introducing AT as an alternative MSC source, donor availability for co-culture expansions will be significantly improved. Both these points will facilitate the definition of MSC donor acceptance criteria, contributing towards process standardization and current good manufacturing practices (GMP) compliance.

Ultimately, by aiming at the production of clinicalgrade expanded UCB HSPC, we envision exploring the scalability of the co-culture system using AT MSC to evaluate the feasibility of attaining numbers with clinical significance. Our co-culture system is currently limited to a $2 \mathrm{D}$ surface and performed in static conditions. Translating the co-culture setting into a $3 \mathrm{D}$ environment (e.g., using a scaffold for MSC anchorage) and developing a bioreactor to introduce dynamic flow could help improve its scalability and overall viability in producing a potential approved cell-based product. At the same time, it would be important to investigate and clarify the differences and/or similarities behind the supportive hematopoietic capacity of each MSC source at a cellular level. If they could be tracked to individual cell features (e.g., MSC-derived soluble cytokines, extracellular vesicles, adhesion molecules, extracellular matrix molecules, or other [66]), we could potentiate their effect by bioengineering it in a novel expansion system.

\section{Conclusions}

The capacity of mesenchymal stromal cells (MSC) derived from different sources (bone marrow (BM), umbilical cord matrix (UCM), and adipose tissue $(\mathrm{AT})$ ) to support the expansion/maintenance of umbilical cord blood (UCB) hematopoietic stem/progenitor cells (HSPC) was directly compared in this study. Our results showed that UCB CD34 $4^{+}$-enriched cells were better expanded, while preserving the stem/progenitor content, over a feeder layer (FL) of MSC derived from AT. Of note, in addition to myeloid committed cells (e.g., 
$\mathrm{CD}^{+} 3^{+}, \mathrm{CD} 14^{+}, \mathrm{CD} 41 \alpha^{+}$and $\mathrm{CD} 15^{+}$cells), a substantial population of progenitor $\mathrm{T}$ cells $\left(\mathrm{CD} 34^{+} \mathrm{CD} 7^{+}\right.$cells) was also maintained and expanded. On the other hand, the expansion capacity of UCB cells was significantly decreased when expanded over a UCM-derived MSC FL. We went further by exploring if MSC FL established using serum-free (SF)/xenogeneic-free (XF) conditions, i.e., using fibrinogen-depleted human platelet lysate (HPL) instead of fetal bovine serum (FBS), would impact the already established SF co-culture system. While the expansion capacity was not affected by this alteration, we noticed a shift from hematopoietic progenitors to more differentiated cells. Still, further studies are needed to fully understand the impact of using HPL (instead of the commonly used FBS) in MSC FL establishment in what concerns its ability to support human HSPC in vitro.

Overall, our study provides important insights concerning the possibility of expanding UCB HSPC in a coculture system with MSC, derived from other more accessible sources than BM and in a SF/XF context, paving the way towards clinical translation. Also, the developed protocols used herein show a high compatibility with current good manufacturing practices (GMP), since few adjustments would be needed, including the use of the CliniMACS platform (for $\mathrm{CD}_{3} 4^{+}$cell purification) and the incorporation of a clinical-grade XF hematopoietic expansion medium until a suitable fully chemically defined version can be adopted.

\begin{abstract}
Abbreviations
A/A: Antibiotic-antimycotic; AT: Adipose tissue; BFU-E: Erythroid burstforming unit; BM: Bone marrow; CAFC: Cobblestone area-forming cells; CFU: Colony-forming unit; CFU-GM: Colony-forming unit granulocytemonocyte; CFU-Mix: Multilineage colony-forming unit; DMEM: Dulbecco's modified Eagle's medium; EDTA: Ethylenediamine tetraacetic acid; FBS: Fetal bovine serum; Fl: Fold increase; FL: Feeder layer; GMP: Good manufacturing practices; GVHD: Graft-vs-host disease; HCT: Hematopoietic cell transplantation; HPL: Human platelet lysate; HSPC: Hematopoietic stem/ progenitor cells; iBB: Institute for Bioengineering and Biosciences; ISCT: International Society for Cell \& Gene Therapy; IST: Instituto Superior Técnico; LTC-IC: Long-term culture-initiating cells; MACS: Magnetic-activated cell sorting; MNC: Mononuclear cells; MSC: Mesenchymal stromal cells; PBS: Phosphate-buffered saline; SCERG: Stem Cell Engineering Research Group; SF: Serum-free; SVF: Stromal vascular fraction; TNC: Total nucleated cells; UCB: Umbilical cord blood; UCM: Umbilical cord matrix; USA: United States of America; XF: Xenogeneic-free
\end{abstract}

\section{Acknowledgements}

We would like to acknowledge the Hospital São Francisco Xavier - Centro Hospitalar de Lisboa Ocidental, Instituto Português de Oncologia Francisco Gentil and Clínica de Todos-os-Santos for their kind donations of UCB and tissue, BM and AT samples, respectively, for this study. We would like to acknowledge AventaCell Biomedical Corp., USA, for providing the human platelet lysate supplement (UltraGROTM_PURE) for this study, within the framework of their collaboration with IST-iBB.

\section{Authors' contributions}

$\mathrm{SB}, \mathrm{AFP}$, and $\mathrm{CLS}$ designed the research study. SB conducted the experiments and analyzed the data. $\mathrm{AB}$ and $\mathrm{MM}$ conducted the experiments, JCM performed umbilical cord blood collection, as well as donor screening and evaluation of donor suitability for our study. SB, AFP, and CLS wrote the manuscript. All authors critically revised and approved the final manuscript.

\section{Authors' information}

Current affiliation of MM is Cell and Gene Therapy Catapult, 12th Floor Tower Wing, Guy's Hospital, London, UK.

\section{Funding}

This work was funded by iBB-IST through FCT - Portuguese Foundation for Science and Technology (UIDB/04565/2020). We also acknowledge the funding received from the project MSCellProduction (POCI-01-0247-FEDER-

038313) funded by Portugal 2020, under Programa Operacional Competitividade e Internacionalização, and by the European Regional Development Fund. Sara Bucar and André Branco acknowledge FCT for their PhD fellowships SFRH/BD/128379/2017 and SFRH/BD/132665/2017, respectively.

\section{Availability of data and materials}

Please contact the corresponding author for data requests.

\section{Declarations}

\section{Ethics approval and consent to participate}

Human samples were obtained from local hospitals (UCB and tissue: Hospital São Francisco Xavier, Centro Hospitalar de Lisboa Ocidental; BM: Instituto Português de Oncologia Francisco Gentil, Lisboa; AT: Clínica de Todos-osSantos, Lisboa) under collaboration agreements with Institute for iBB-IST, after written and informed consent and according to the Directive 2004/23/ EC of the European Parliament and of the Council of 31 March 2004 regarding standards of quality and safety for the donation, procurement, testing, processing, preservation, storage, and distribution of human tissues and cells (Portuguese Law 22/2007). All samples used in this study were obtained from human donors (the mothers, in the case of UCB and tissue) that have previously tested negative for common virus and diseases.

\section{Consent for publication}

N/A

\section{Competing interests}

The authors declare that they have no competing interests.

\section{Author details}

${ }^{1}$ Department of Bioengineering and iBB - Institute for Bioengineering and Biosciences, Instituto Superior Técnico, Universidade de Lisboa, Lisboa, Portugal. ${ }^{2}$ Associate Laboratory i4HB - Institute for Health and Bioeconomy, Instituto Superior Técnico, Universidade de Lisboa, Lisboa, Portugal. ${ }^{3} \mathrm{H}$ ospital São Francisco Xavier, Centro Hospitalar de Lisboa Ocidental, Lisboa, Portugal.

${ }^{4}$ Instituto Gulbenkian de Ciência, Oeiras, Portugal.

Received: 17 March 2021 Accepted: 24 June 2021

Published online: 13 July 2021

\section{References}

1. Phelan R, Arora M, Chen M. Current use and outcome of hematopoietic stem cell transplantation: CIBMTR US summary slides; 2020

2. Mayani H, Wagner JE, Broxmeyer HE. Cord blood research, banking, and transplantation: achievements, challenges, and perspectives. Bone Marrow Transplant. 2020;55(1):48-61. https://doi.org/10.1038/s41409-019-0546-9.

3. Oran B, Shpall E. Umbilical cord blood transplantation: a maturing technology. Hematology. 2012;2012(1):215-22. https://doi.org/10.1182/a sheducation.V2012.1.215.3798291.

4. Shpall EJ, Quinones R, Giller R, Zeng C, Baron AE, Jones RB, et al. Transplantation of ex vivo expanded cord blood. Biol Blood Marrow Transplant. 2002;8(7):368-76. https://doi.org/10.1053/bbmt.2002.v8.pm121 71483.

5. Sideri A, Neokleous N, Grange PB de la G, Guerton B, Kerdilles MC le B, Uzan $G$, et al. An overview of the progress on double umbilical cord blood transplantation. Haematologica. 2011;96(8):1213-20. https://doi.org/10.3324/ haematol.2010.038836

6. Kiernan J. Damien P, Monaghan M, Shorr R, Mclntyre L, Fergusson D, et al. Clinical studies of ex vivo expansion to accelerate engraftment after 
umbilical cord blood transplantation: a systematic review. Transfus Med Rev. 2017;31(3):173-82. https://doi.org/10.1016/j.tmrv.2016.12.004.

7. Wilkinson AC, Igarashi KJ, Nakauchi H. Haematopoietic stem cell self-renewal in vivo and ex vivo. Nat Rev Genet. 2020;21(9):541-54. https://doi.org/10.103 8/541576-020-0241-0.

8. Costa MHG, de Soure AM, Cabral JMS, Ferreira FC, da Silva CL. Hematopoietic niche - exploring biomimetic cues to improve the functionality of hematopoietic stem/progenitor cells. Biotechnol J. 2018; 13(2). https://doi.org/10.1002/biot.201700088.

9. Da Silva CL, Gonçalves R, Crapnell KB, Cabral JMS, Zanjani ED, AlmeidaPorada G. A human stromal-based serum-free culture system supports the ex vivo expansion/maintenance of bone marrow and cord blood hematopoietic stem/progenitor cells. Exp Hematol. 2005;33(7):828-35. https://doi.org/10.1016/j.exphem.2005.03.017.

10. da Silva CL, Gonçalves R, dos Santos F, Andrade PZ, Almeida-Porada G, Cabral JMS. Dynamic cell-cell interactions between cord blood haematopoietic progenitors and the cellular niche are essential for the expansion of CD34 +, CD34 + CD38 - and early lymphoid CD7 + cells. J Tissue Eng Regen Med. 2010;4(2):149-58. https://doi.org/10.1002/term.226.

11. Andrade PZ, Soure AM, Santos F, Paiva A, Cabral JMS, Silva CL. Ex vivo expansion of cord blood haematopoietic stem/progenitor cells under physiological oxygen tensions: clear-cut effects on cell proliferation, differentiation and metabolism. J Tissue Eng Regen Med. 2015;9(10):117281. https://doi.org/10.1002/term.1731.

12. Branco A, Bucar S, Moura-Sampaio J, Lilaia C, Cabral JM, FernandesPlatzgummer A, et al. Tailored cytokine optimization for ex vivo culture platforms targeting the expansion of human hematopoietic stem/ progenitor cells. Front Bioeng Biotechnol. 2020;8(September):1-21. https:// doi.org/10.3389/fbioe.2020.573282.

13. De Lima M, McNiece I, Robinson SN, Munsell M, Eapen M, Horowitz M, et al. Cord-blood engraftment with ex vivo mesenchymal-cell coculture. N Engl J Med. 2012;367(24):2305-15. https://doi.org/10.1056/NEJMoa1207285.

14. MacMillan ML, Blazar BR, DeFor TE, Wagner JE. Transplantation of ex-vivo culture-expanded parental haploidentical mesenchymal stem cells to promote engraftment in pediatric recipients of unrelated donor umbilical cord blood: results of a phase I-II clinical trial. Bone Marrow Transplant. 2009;43(6):447-54. https://doi.org/10.1038/bmt.2008.348.

15. Bernardo ME, Ball LM, Cometa AM, Roelofs H, Zecca M, Avanzini MA, et al. Co-infusion of ex vivo-expanded, parental MSCs prevents life-threatening acute GVHD, but does not reduce the risk of graft failure in pediatric patients undergoing allogeneic umbilical cord blood transplantation. Bone Marrow Transplant. 2011;46(2):200-7. https://doi.org/10.1038/bmt.2010.87.

16. Galipeau J, Sensébé L. Mesenchymal stromal cells: clinical challenges and therapeutic opportunities. Cell Stem Cell. 2018;22(6):824-33. https://doi. org/10.1016/j.stem.2018.05.004.

17. Brown C, McKee C, Bakshi S, Walker K, Hakman E, Halassy S, et al. Mesenchymal stem cells: cell therapy and regeneration potential. J Tissue Eng Regen Med. 2019;13(9):1738-55. https://doi.org/10.1002/term.2914.

18. Bunnell BA, Flaat M, Gagliardi C, Patel B, Ripoll C. Adipose-derived stem cells: isolation, expansion and differentiation. Methods. 2008:45(2):115-20. https://doi.org/10.1016/j.ymeth.2008.03.006.

19. Han J, Koh YJ, Moon HR, Ryoo HG, Cho CH, Kim I, et al. Adipose tissue is an extramedullary reservoir for functional hematopoietic stem and progenitor cells. Blood. 2010;115(5):957-64. https://doi.org/10.1182/blood-2009-05-21 9923.

20. Kilroy GE, Foster SJ, Wu X, Ruiz J, Sherwood S, Heifetz A, et al. Cytokine profile of human adipose-derived stem cells: expression of angiogenic, hematopoietic, and pro-inflammatory factors. J Cell Physiol. 2007;212(3):7029. https://doi.org/10.1002/jcp.21068.

21. Andreeva ER, Andrianova IV, Sotnezova EV, Buravkov SV, Bobyleva Pl, Romanov YA, et al. Human adipose-tissue derived stromal cells in combination with hypoxia effectively support ex vivo expansion of cord blood haematopoietic progenitors. PLoS One. 2015;10(4):1-14.

22. Andreeva E, Andrianova I, Bobyleva P, Gornostaeva A, Ezdakova M, Golikova E, et al. Adipose tissue-derived stromal cells retain immunosuppressive and angiogenic activity after coculture with cord blood hematopoietic precursors. Eur J Cell Biol. 2020;99(2-3):151069. https://doi.org/10.1016/j. ejcb.2020.151069.

23. Simões IN, Boura JS, Dos Santos F, Andrade PZ, Cardoso CMP, Gimble JM, et al. Human mesenchymal stem cells from the umbilical cord matrix: Successful isolation and ex vivo expansion using serum-/xeno-free culture media. Biotechnol J. 2013;8(4):448-58. https://doi.org/10.1002/biot.20120034 0.

24. Zhao D, Liu L, Chen Q, Wang F, Li Q, Zeng Q, et al. Hypoxia with Wharton's jelly mesenchymal stem cell coculture maintains stemness of umbilical cord blood-derived CD34 + cells. Stem Cell Res Ther. 2018;9(1):1-11.

25. Kern S, Eichler H, Stoeve J, Klüter H, Bieback K. Comparative analysis of mesenchymal stem cells from bone marrow, umbilical cord blood, or adipose tissue. Stem Cells. 2006;24(5):1294-301. https://doi.org/10.1634/ stemcells.2005-0342.

26. Jin HJ, Bae YK, Kim M, Kwon SJ, Jeon HB, Choi SJ, et al. Comparative analysis of human mesenchymal stem cells from bone marrow, adipose tissue, and umbilical cord blood as sources of cell therapy. Int J Mol Sci. 2013;14(9): 17986-8001. https://doi.org/10.3390/ijms140917986.

27. Dehn J, Spellman S, Hurley CK, Shaw BE, Barker JN, Burns LJ, et al. Selection of unrelated donors and cord blood units for hematopoietic cell transplantation: guidelines from the NMDP/CIBMTR. Blood. 2019;134(12): 924-34. https://doi.org/10.1182/blood.2019001212.

28. Hemeda H, Giebel B, Wagner W. Evaluation of human platelet lysate versus fetal bovine serum for culture of mesenchymal stromal cells. Cytotherapy. 2014;16(2):170-80. https://doi.org/10.1016/j.jcyt.2013.11.004.

29. Dos Santos F, Andrade PZ, Boura JS, Abecasis MM, Da Silva CL, Cabral JMS. Ex vivo expansion of human mesenchymal stem cells: a more effective cell proliferation kinetics and metabolism under hypoxia. J Cell Physiol. 2010; 223(1):27-35. https://doi.org/10.1002/jcp.21987.

30. Pinto DS, Ahsan T, Serra J, Fernandes-Platzgummer A, Cabral JMS, da Silva $\mathrm{CL}$. Modulation of the in vitro angiogenic potential of human mesenchymal stromal cells from different tissue sources. J Cell Physiol. 2020;235(10):722438. https://doi.org/10.1002/jcp.29622.

31. Serra J, Alves CPA, Cabral JMS, Monteiro GA, da Silva CL, Prazeres DMF. Minicircle-based expression of vascular endothelial growth factor in mesenchymal stromal cells from diverse human tissues. J Gene Med. 2021; (April):1-12.

32. Loeuillet $C$, Bernard $G$, Rémy-Martin JP, Saas $P$, Hervé $P$, Douay $L$, et al. Distinct hematopoietic support by two human stromal cell lines. Exp Hematol. 2001;29(6):736-45. https://doi.org/10.1016/50301-472X(01)00644-0.

33. Wang HX, Gao XW, Ren B, Cai Y, Li WJ, Yang YL, et al. Comparative analysis of different feeder layers with $3 \mathrm{~T} 3$ fibroblasts for culturing rabbits limbal stem cells. Int J Ophthalmol. 2017;10(7):1021-7. https://doi.org/10.18240/ ijo.2017.07.01.

34. Denning-Kendall P, Singha S, Bradley B, Hows J. Cobblestone area-forming cells in human cord blood are heterogeneous and differ from long-term culture-initiating cells. Stem Cells. 2003;21(6):694-701. https://doi.org/10.1 634/stemcells.21-6-694.

35. Stolzing A, Jones E, McGonagle D, Scutt A. Age-related changes in human bone marrow-derived mesenchymal stem cells: consequences for cell therapies. Mech Ageing Dev. 2008;129(3):163-73. https://doi.org/10.1016/j. mad.2007.12.002.

36. Grégoire C, Ritacco C, Hannon M, Seidel L, Delens L, Belle L, et al. Comparison of mesenchymal stromal cells from different origins for the treatment of graft-vs.-host-disease in a humanized mouse model. Front Immunol. 2019;10:1-16.

37. Ribeiro A, Laranjeira P, Mendes S, Velada I, Leite C, Andrade P, et al. Mesenchymal stem cells from umbilical cord matrix, adipose tissue and bone marrow exhibit different capability to suppress peripheral blood B, natural killer and T cells. Stem Cell Res Ther. 2013;4(5):125.

38. Radtke S, Pande D, Cui M, Perez AM, Chan YY, Enstrom M, et al. Purification of human CD34+CD90+ HSCs reduces target cell population and improves lentiviral transduction for gene therapy. Mol Ther - Methods Clin Dev. 2020; 18(September):679-91. https://doi.org/10.1016/j.omtm.2020.07.010.

39. Ploemacher R, van der Sluijs J, Voerman J, Brons N. An in vitro limitingdilution assay of long-term repopulating hematopoietic stem cells in the mouse. Blood. 1989;74(8):2755-63. https://doi.org/10.1182/blood.V74.8.2 755.2755 .

40. Singh J, Chen ELY, Xing Y, Stefanski HE, Blazar BR, Zúñiga-Pflücker JC. Generation and function of progenitor $t$ cells from stemregenin-1-expanded CD34+ human hematopoietic progenitor cells. Blood Adv. 2019;3(20):293448. https://doi.org/10.1182/bloodadvances.2018026575.

41. Awong G, Herer E, Surh CD, Dick JE, La Motte-Mohs RN, Zúñiga-Pflücker JC. Characterization in vitro and engraftment potential in vivo of human progenitor T cells generated from hematopoietic stem cells. Blood. 2009; 114(5):972-82. https://doi.org/10.1182/blood-2008-10-187013. 
42. Szabolcs P. T lymphocyte recovery and function after cord blood transplantation. Immunol Res. 2011;49(0):56-69, 1-3, DOl: https://doi.org/10.1 007/s12026-010-8194-6.

43. Singh J, Zúñiga-Pflücker JC. Producing proT cells to promote immunotherapies. Int Immunol. 2018;30(12):541-50. https://doi.org/10.1093/ intimm/dxy051.

44. Frias AM, Porada CD, Crapnell KB, Cabral JMS, Zanjani ED, Almeida-Porada G. Generation of functional natural killer and dendritic cells in a human stromal-based serum-free culture system designed for cord blood expansion. Exp Hematol. 2008;36(1):61-8. https://doi.org/10.1016/j.exphem.2 007.08.031.

45. Kim HS, Shin TH, Lee BC, Yu KR, Seo Y, Lee S, et al. Human umbilical cord blood mesenchymal stem cells reduce colitis in mice by activating NOD2 signaling to COX2. Gastroenterology. 2013;145(6):1392-1403.e8.

46. Li CY, Wu XY, Tong JB, Yang XX, Zhao JL, Zheng QF, et al. Comparative analysis of human mesenchymal stem cells from bone marrow and adipose tissue under xeno-free conditions for cell therapy. Stem Cell Res Ther. 2015; 6(1):55.

47. Petrenko Y, Vackova I, Kekulova K, Chudickova M, Koci Z, Turnovcova K, et al. A comparative analysis of multipotent mesenchymal stromal cells derived from different sources, with a focus on neuroregenerative potential. Sci Rep. 2020;10(1):1-15.

48. Ding DC, Shyu WC, Lin SZ, Liu HW, Chiou SH, Chu TY. Human umbilical cord mesenchymal stem cells support nontumorigenic expansion of human embryonic stem cells. Cell Transplant. 2012;21(7):1515-27. https://doi.org/1 $0.3727 / 096368912 \times 647199$.

49. Zou Q, Wu M, Zhong L, Fan Z, Zhang B, Chen Q, et al. Development of a xeno-free feeder-layer system from human umbilical cord mesenchymal stem cells for prolonged expansion of human induced pluripotent stem cells in culture. PLoS One. 2016:11(2):1-18.

50. Fong CY, Gauthaman K, Cheyyatraivendran S, Lin HD, Biswas A, Bongso A. Human umbilical cord Wharton's jelly stem cells and its conditioned medium support hematopoietic stem cell expansion ex vivo. J Cell Biochem. 2012:113(2):658-68. https://doi.org/10.1002/jcb.23395.

51. Lin $H D$, Fong $C Y$, Biswas $A$, Bongso A. Allogeneic human umbilical cord Wharton's jelly stem cells increase several-fold the expansion of human cord blood CD34+ cells both in vitro and in vivo. Stem Cell Res Ther. 2020; 11(1):1-18, 527, DOI: https://doi.org/10.1186/s13287-020-02048-0.

52. Ponchio L, Duma L, Oliviero B, Gibelli N, Pedrazzoli P, Della Cuna GR. Mitomycin $C$ as an alternative to irradiation to inhibit the feeder layer growth in long-term culture assays. Cytotherapy. 2000;2(4):281-6. https:// doi.org/10.1080/146532400539215.

53. Kadekar D, Kale V, Limaye L. Differential ability of MSCs isolated from placenta and cord as feeders for supporting ex vivo expansion of umbilical cord blood derived CD34+ cells. Stem Cell Res Ther. 2015 Dec 19:6(1):201. https://doi.org/10.1186/s13287-015-0194-y.

54. Klein C, Strobel J, Zingsem J, Richter RH, Goecke TW, Beckmann MW, et al. Ex Vivo expansion of hematopoietic stem-and progenitor cells from cord blood in coculture with mesenchymal stroma cells from amnion, chorion, Wharton's jelly, amniotic fluid, cord blood, and bone marrow. Tissue Eng Part A. 2013:19(23-24):2577-85. https://doi.org/10.1089/ten.tea.2013.0073.

55. Introna M, Lucchini G, Dander E, Galimberti S, Rovelli A, Balduzzi A, et al. Treatment of graft versus host disease with mesenchymal stromal cells: a phase I study on 40 adult and pediatric patients. Biol Blood Marrow Transplant. 2014;20(3):375-81. https://doi.org/10.1016/j.bbmt.2013.11.033.

56. Dhere T, Copland I, Garcia M, Chiang KY, Chinnadurai R, Prasad M, et al. The safety of autologous and metabolically fit bone marrow mesenchymal stromal cells in medically refractory Crohn's disease - a phase 1 trial with three doses. Aliment Pharmacol Ther. 2016;44(5):471-81. https://doi.org/1 0.1111/apt.13717.

57. Burnouf T, Strunk D, Koh MBC, Schallmoser K. Human platelet lysate: replacing fetal bovine serum as a gold standard for human cell propagation? Biomaterials. 2016;76:371-87. https://doi.org/10.1016/j.bioma terials.2015.10.065.

58. Abdelrazik H, Spaggiari GM, Chiossone L, Moretta L. Mesenchymal stem cells expanded in human platelet lysate display a decreased inhibitory capacity on T- and NK-cell proliferation and function. Eur J Immunol. 2011; 41(11):3281-90. https://doi.org/10.1002/eji.201141542.

59. Oikonomopoulos A, Van Deen WK, Manansala AR, Lacey PN, Tomakili TA, Ziman A, et al. Optimization of human mesenchymal stem cell manufacturing: the effects of animal/xeno-free media. Sci Rep. 2015; 5(October):1-11.

60. Copland IB, Garcia MA, Waller EK, Roback JD, Galipeau J. The effect of platelet lysate fibrinogen on the functionality of MSCs in immunotherapy. Biomaterials. 2013;34(32):7840-50. https://doi.org/10.1016/j.biomaterials.2013. 06.050 .

61. Nakao N, Nakayama T, Yahata T, Muguruma Y, Saito S, Miyata Y, et al. Adipose tissue-derived mesenchymal stem cells facilitate hematopoiesis in vitro and in vivo: advantages over bone marrow-derived mesenchymal stem cells. Am J Pathol. 2010;177(2):547-54. https://doi.org/10.2353/ajpath.2 010.091042

62. Nishiwaki S, Nakayama T, Saito S, Mizuno H, Ozaki T, Takahashi Y, et al. Efficacy and safety of human adipose tissue-derived mesenchymal stem cells for supporting hematopoiesis. Int J Hematol. 2012;96(3):295-300. https://doi.org/10.1007/s12185-012-1140-8.

63. Lee RH, Kim BC, Choi IS, Kim H, Choi HS, Suh KT, et al. Characterization and expression analysis of mesenchymal stem cells from human bone marrow and adipose tissue. Cell Physiol Biochem. 2004;14(4-6):311-24. https://doi. org/10.1159/000080341.

64. Sotnezova EV, Andreeva ER, Grigoriev Al, Buravkova LB. Ex vivo expansion of hematopoietic stem and progenitor cells from umbilical cord blood. Acta Naturae. 2016;8(3):6-16. https://doi.org/10.32607/20758251-2016-8-3-6-16.

65. Li Q, Zhao D, Chen Q, Luo M, Huang J, Yang C, et al. Wharton's jelly mesenchymal stem cell-based or umbilical vein endothelial cell-based serum-free coculture with cytokines supports the ex vivo expansion/ maintenance of cord blood hematopoietic stem/progenitor cells. Stem Cell Res Ther. 2019;10(1):1-9.

66. Fajardo-Orduña GR, Mayani H, Montesinos JJ. Hematopoietic support capacity of mesenchymal stem cells: biology and clinical potential. Arch Med Res. 2015;46(8):589-96. https://doi.org/10.1016/j.arcmed.2015.10.001.

\section{Publisher's Note}

Springer Nature remains neutral with regard to jurisdictional claims in published maps and institutional affiliations.

Ready to submit your research? Choose BMC and benefit from

- fast, convenient online submission

- thorough peer review by experienced researchers in your field

- rapid publication on acceptance

- support for research data, including large and complex data types

- gold Open Access which fosters wider collaboration and increased citations

- maximum visibility for your research: over $100 \mathrm{M}$ website views per year

At $\mathrm{BMC}$, research is always in progress.

Learn more biomedcentral.com/submissions 